\title{
Open Angle Glaucoma, Glaucoma Suspect And Ocular Hypertention In Thyroid Related Immune Orbitopathy And Other Thyroid Diseases
}

\author{
Saleha Sultana ${ }^{1}$, Syed Abdul Wadud ${ }^{2}$, Shabeena Huda ${ }^{3}$, Sharfuddin Ahmed ${ }^{4}$ \\ ${ }^{1}$ Resident, ${ }^{2}$ Associate Professor, ${ }^{3}$ Assistant Professor, ${ }^{4}$ Professor Department of community ophthalmology, BSMMU.
}

\begin{abstract}
:
Background: The eye changes associated with thyroid disease are referred to as Thyroid related Orbitopathy. A well described association exist between open angle glaucoma and thyroid related orbitopathy, the possible relationship between open angle glaucoma and either hypothyroidism or hyperthyroidism without orbitopathy is variable. Objective: To observe the relation of open angle glaucoma (OAG), glaucoma suspect (GS) and ocular hypertension(OHT) between Thyroid related immune orbitopathy (TRIO) and other thyroid diseases (toxic multinodular goiter and hypothyroidism). Method: With purposive type of sampling technique 40 patients of Graves' disease disease in Group-A and 40 patients of other thyroid diseases in Group-B which was subdivided into 20 patients of toxic multinodular goiter in Group-B1, 20 patients of hypothyroidism in Group-B2 were selected in Bangabandhu Sheikh Mujib Medical University (BSMMU) for this cross sectional study. The diagnosis of Graves' disease, toxic multinodular goiter and hypothyroidism were carried out by history, clinical examination and clinical test in endocrinology department. All the patients underwent complete ocular examinations, measuring of intraocular pressure (IOP), fundus examination, visual field analysis, gonioscopy and exophthalmometry. Result: The OAG, GS and OHT was 7.5\% (3 cases), 5.0\% ( 2 cases) and 17.5\% ( 7 cases) respectively in Group-A. In contrast OAG, GS was 5\% (1 case), 5\% (1 case) respectively in Group-B1, only 5\% (1 case) OAG in Group-B2. There was no incidence of OHT in Group-B $(B 1+B 2)$. Although the occurrence of OAG and GS were higher in Group-A than Group-B, this difference was not statistically significant $(\mathrm{p}>0.05)$. However OHT was more common in Group-A than Group-B and is statistically significant $(p<0.05)$. Among the 12 patients with OAG, GS and OHT in Group-A, 11 had $\geq 22 \mathrm{~mm}$ exophthalmos. In Group-A, $\geq 22 \mathrm{~mm}$ exophthalmos in $60 \%$ cases, in contrast none of Group-B have $\geq 22 \mathrm{~mm}$. Conclusion: The occurrence of OHT was higher in thyroid related immune orbitopathy than other thyroid diseases.
\end{abstract}

Key words: Thyroid related immune orbitopathy, opon angle glaucoma, glaucoma suspect, ocular hypertension.

[BSMMU J $2015 ; 8(1): 50-55]$

\section{Introduction:}

Thyroid eye disease (TED); known as Grave ophthalmopathy, dysthyroid ophthalmopathy, thyroid associated orbitopathy, thyrotoxic exophthalmos and other terms. Graves' disease is an autoimmune condition in which autoantibodies. Address for Correspondence: Dr. Saleha Sultana, Resident, Department of Community Ophthalmology, BSMMU.

Target the thyroid stimulating hormone receptor (TSH-R) displayed on thyrocytes, inducing the production of excess thyroid hormone'. Graves' orbitopathy is a part of

Address for Correspondence: : Dr Saleha Sultana, Resident, Department of Community Ophthalmology, BSMMU.

Mobile : 01716159262 , E-mail: sspushpo@gmail.com. a systemic process with variable expression in the eyes, thyroid and skin caused by auto antibodies that bind to tissue in these organs and in general occurs with hyperthyroidism ${ }^{2}$. Thyroid problem have been reported in over 110 countries of the world with 1.6 billion at risk and most of these are in developing countries ${ }^{3}$.

Although TRO is seen in all types of thyroid disorder, it is most common in patients who are or were hyperthyroid. TRO occurs in about 1 out of 20 people that were hyperthyroid. It can also rarely occur in those who are hypothyroid and even when there is an absence of thyroid abnormalities in the body ${ }^{4}$. Graves' disease, the most common subtype of hyperthyroidism ${ }^{5}$. Most patients with Graves' ophthalmopathy have autoimmune thyroid dysfunction especially hyperthyroidism or Graves' disease; which 
occurs in $90 \%$ cases $^{6}$. Depending on the sensitivity of orbitopathy the prevalence of eye disease in patients with Graves' disease ranges from 25 to $70 \%{ }^{7}$. Graves' orbitopathy is characterized by eyelid retraction, eyelid swelling, keratitis, proptosis, restrictive myopathy, elevated intraocular pressure on up gaze and impaired visual acuity and visual field defect in severe cases ${ }^{8}$. Multinodular goiter is the enlargement of thyroid gland due to repeated episodes of hyperplasia and involution of simple goiter. In toxic multinodular goiter the amount of thyroid hormone is higher than normal and high radioiodine uptake, in toxic multinodular goiter thyroid hormone is elevated. A toxic multinodular goiter is 2 nd most common cause of hyperthyroidism ${ }^{9}$.

Globally, iodine deficiency contributes to the vast majority of cases of multinodular goiter and affects $30 \%(1.5$ billion) of world's population. In 1994, in Bangladesh approximately $47 \%$ of populations were affected by goiter $^{10}$.

Many structural or functional abnormalities can impair the production of thyroid hormones and cause the clinical state termed hypothyroidism" ${ }^{\prime \prime}$ The prevalence of hypothyroidism in developed world is about $4-5 \%{ }^{12}$. Paul et al states that, in a survey performed in Khulna the incidence of hypothyroidism is $4.97 \%{ }^{13}$. Cross et al states that, thyroid disorder may increase the risk of glaucoma ${ }^{14}$. The prevalence of autoimmune thyroid disease is quite high in Bangladesh ${ }^{15}$

Glaucoma is a multifactorial disease characterized by a loss of retinal ganglion cells that leads to typical damage of the optic nerve and visual field. Glaucoma blindness ranking only second to cataract (19.3 million) as a cause of blindness worldwide ${ }^{16}$.

The number of people with primary open angle glaucoma in the world by the year 2000 is estimated at nearly 66.8 million; with 6.7 million suffering from bilateral blindness ${ }^{17}$.Approximately $70 \%$ of glaucoma is found in developing countries ${ }^{18}$.

It is estimated that there are approximately 6 lack people of 40 years and older with definite or probable glaucoma in Bangladesh ${ }^{19}$. Open angle glaucoma(OAG) was defined as glaucomatous changes in optic nerve with corresponding visual field defects and high or normal IOP in presence of an open angle ${ }^{20}$. A glaucoma suspect is defined as an adult who has one of following findings in at least in one eye : 1. An optic nerve or nerve fiber layer defect suggestive of glaucoma, 2. A visual field abnormality consistent with glaucoma, 3. An elevated IOP greater than $21 \mathrm{mmHg}$. About 4 to $7 \%$ of the population over the age of 40 years have IOPs $>21 \mathrm{mmHg}$ without detectable glaucomatous damage have ocular hypertension ${ }^{21}$.

A well described association exist between open angle glaucoma and thyroid related orbitopathy, the possible relationship between open angle glaucoma and either hypothyroidism or hyperthyroidism without orbitopathy is variable $\mathrm{e}^{22}$.

Significant relationships have been demonstrated between thyroid associated orbitopathy with open angle glaucoma and ocular hypertension (OHT), and dysthyroid optic neuropathy ${ }^{23-24}$.

This study was carried out to evaluate the IOP, fundoscopy, gonioscopy and visual field analysis in diagnosed cases of thyroid abnormality attending at the department of endocrinology and ophthalmology in BSMMU.

This study will be helpful for early diagnosis of glaucoma associated with thyroid abnormality and preventing blindness due to it. It would also aware physicians as well as ophthalmologists about importance of ocular evaluation of all thyroid disease patients regularly which will be beneficial for patients as well as for the country.

\section{Methods:}

This cross sectional study was carried out in Department of Community Ophthalmology, BSMMU,Shahbagh, Dhaka, Bangladesh from April' 2013 to March' 2014. Informed written consent was taken from the patients. In this cross sectional purposive type of sampling two groups of thyroid disease patients included. Patients attended in the Department of Ophthalmology, Community Ophthalmology and Endocrinology, BSMMU, who were diagnosed as cases of Thyroid associated orbitopathy, toxic multinodular goiter, hyperthyroidism were the source of the study.

The group-A includes 40 patients of diagnosed cases of Graves disease with ocular involvement and Group-B includes 40 patients of other thyroid diseases presented with ocular symptoms which was subdivided into 20 patients of toxic multinodular goiter in Group-B1, 20 patients of hypothyroidism in Group-B2.

Clinical evaluation including history, physical examina- 
tion, relevant ocular examinations and some special ocular examinations like, intraocular pressure measurement, visual field analysis, gonioscopy, fundus examination was done in Community Ophthalmology department as per prepared data collection sheet.

\section{Ocular examinations included:}

Best corrected visual acuity (BCVA): Recorded with Snellen's test chart and then converted to Log MAR visual acuity, Ocular motility, Slit lamp examination of anterior segment, Slit lamp examination of anterior chamber angle with the help of Goldmann 3 mirror gonioscope (gonioscopy), Fundus examination with the help of +90D/+78D condensing lens, IOP measurement in primary and up gaze by Goldmann applanation tonometer in morning $(8,11 \mathrm{am})$ and evening $(2,4 \mathrm{pm})$. In cases of IOP $>21 \mathrm{mmHg}$ at any time, the measurement was repeated the next day at the same time and by the same person. Cases with raised IOP in two subsequent measurements was considered as elevated IOP. The difference of IOP between primary and up gaze $>6 \mathrm{mmHg}$ is significant, called differential IOP. The significance of the increased IOP on up gaze in the diagnosis of Graves' ophthalmopathy and its normal range are controversial. Increased IOP on up gaze correlated positively with the severity of exophthalmos. The clinical sensitivity and specificity of this increase in IOP, especially in up gaze, has been debated, although its exercise has not. The diminution in scleral rigidity seen in thyrotropic exophthalmos is not only a diagnostic aid but also makes ii possible to demonstrate ocular hy $\neg$ pertension, but sclera rigidity was not evaluated in this study.

Proptosis by Hertels exophthalmometer, any measurement $>21 \mathrm{~mm} /$ difference between two eyes $>2 \mathrm{~mm}$ was recorded as abnormal ( exophthalmos), Standard static automated visual field was obtained (Humphrey static perimetry). Glaucoma changes in the optic nerve was defined as cup disc ratio of $>0.6$, vertical cup asymmetiy $>0.2$, NRR loss or notching with or without hemorrhage and nerve fiber layer defect.

Open angle glaucoma was defined as glaucomatous changes in the optic nerve with corresponding visual field defect and high/normal IOP in presence of open angle.

Ocular hypertension was applied to case with IOP> $21 \mathrm{mmHg}$, no glaucomatous changes in optic nerve, normal visual field and open angle.

Glaucoma suspect was defined as normal IOP together with glaucomatous optic nerve changes but normal visual field and open angle.

Statistical analysis was carried out by using the Statistical Package for Social Science version 20.0 for Windos (SPSS Inc, Chicago, IL, USA). The mean values were calculated for continuous variable. $P$ values $<0.05$ was considered as statistically significant.

\section{Results:}

In this cross sectional purposive type of sampling two groups of thyroid disease patients included. The group-A includes 40 patients of diagnosed cases of Graves disease with ocular involvement and Group-B includes 40 patients of other thyroid diseases which was subdivided into 20 patients of toxic multinodular goiter in Group-B1, 20 patients of hypothyroidism in Group-B2.

Table-I

Distribution of study patients by intraocular pressure and Fundoscopy $(n=80)$

\begin{tabular}{|c|c|c|c|c|c|c|}
\hline \multirow[t]{2}{*}{ Parameters } & \multicolumn{2}{|c|}{$\begin{array}{l}\text { Group A } \\
\qquad(n=40)\end{array}$} & \multicolumn{2}{|c|}{$\begin{array}{l}\text { Group B1 } \\
(n=20)\end{array}$} & \multicolumn{2}{|c|}{$\begin{array}{l}\text { Group B2 } \\
(n=20)\end{array}$} \\
\hline & $\mathrm{n}$ & $\%$ & $\mathrm{n}$ & $\%$ & $\mathrm{n}$ & $\%$ \\
\hline \multirow{2}{*}{\multicolumn{7}{|c|}{$\begin{array}{l}\text { Intraocular } \\
\text { pressure } \\
(\mathrm{mmHg})\end{array}$}} \\
\hline & & & & & & \\
\hline $11-21$ & 30 & 75.0 & 19 & 95.0 & 19 & 95.0 \\
\hline$>21$ & 10 & 25.0 & 1 & 5.0 & 1 & 5.0 \\
\hline \multicolumn{7}{|l|}{ Fundoscopy } \\
\hline Normal & 35 & 87.5 & 18 & 90.0 & 19 & 95.0 \\
\hline \multicolumn{3}{|c|}{ Glaucomatous change } & 5 & 12.5 & 2 & 10.0 \\
\hline
\end{tabular}

$*=\mathrm{P}<0.05$

Result is shown in number and percentage

$P$ value reached from chi squre test

Group A- TRIO

Group B1- Toxic multinodular goiter

Group B2- Hypothyroidism

$P$ value $<0.05$ significant( $s=$ significant)

$\mathrm{N}=$ Total sample size

Group B1 - Toxic multinodular goiter

Group B2- Hypothyroidism

$P$ value $<0.05$ significant( $s=$ significant)

not significant

Total sample size 


\section{Table-II}

Distribution of study patients by Humphrer visual field analysis $(n=80)$

\begin{tabular}{|c|c|c|c|c|c|c|c|}
\hline \multirow[t]{2}{*}{ Parameters } & \multicolumn{2}{|c|}{$\begin{array}{l}\text { Group A } \\
(n=40)\end{array}$} & \multicolumn{2}{|c|}{$\begin{array}{l}\text { Group B1 } \\
(n=20)\end{array}$} & \multicolumn{2}{|c|}{$\begin{array}{l}\text { Group B2 } \\
(n=20)\end{array}$} & \multirow[t]{2}{*}{$\begin{array}{c}\text { P- } \\
\text { value }\end{array}$} \\
\hline & $\mathrm{N}$ & $\%$ & $\mathrm{n}$ & $\%$ & $\mathbf{n}$ & $\%$ & \\
\hline Normal & 33 & 82.5 & 19 & 95.0 & 19 & 95.0 & \\
\hline Borderline & 4 & 10.0 & 0 & 0.0 & 0 & 0.0 & $0.336 \mathrm{~ns}$ \\
\hline \multicolumn{8}{|l|}{ Glaucomato } \\
\hline us change & 3 & 7.5 & 1 & 5.0 & 1 & 5.0 & \\
\hline
\end{tabular}

Result is shown in number and percentage

$P$ value reached from chi squre test

Group A- TRIO

Group B1- Toxic multinodular goiter

Group B2- Hypothyroidism

$P$ value $<0.05$ significant $(s=$ significant $)$

$\mathrm{N}=$ Total sample size

ns=not significant

\section{Table-III}

Distribution of study patients by Hertels Exophthalmometry $(n=80)$

\begin{tabular}{|c|c|c|c|c|}
\hline $\begin{array}{l}\text { Measurem } \\
\text { ent ( }(\mathrm{mm})\end{array}$ & $\begin{array}{l}\text { Group A } \\
(n=40)\end{array}$ & $\begin{array}{l}\text { Group B1 } \\
(\mathrm{n}=20)\end{array}$ & $\begin{array}{l}\text { Group B2 } \\
(\mathrm{n}=20)\end{array}$ & $\begin{array}{c}\text { P- } \\
\text { value }\end{array}$ \\
\hline
\end{tabular}

$\begin{array}{llllllll}\geq 15 & 0 & 0.0 & 8 & 40.0 & 5 & 25.0 & \\ 16-21 & 16 & 40.0 & 12 & 60.0 & 15 & 75.0 & \\ 22-25 & 23 & 57.5 & 0 & 0.0 & 0 & 0.0 & \\ >25 & 1 & 2.5 & 0 & 0.0 & 0 & 0.0 & \\ \text { Mean } \pm \text { SD } & 21.5 \pm 1.67 & 16.95 \pm 2.33 & 16.0 \pm 1.41 & 0.001 \mathrm{~s} \\ \text { Range (min } & & & & & & & \\ \text {-max) } & 17 & , 27 & 14 & , 19 & 15 & , 20 & \end{array}$

Result is shown in number and percentage

$P$ value reached from ANOVA test for Mean \pm SD

Group A- TRIO

Group B1- Toxic multinodular goiter

Group B2- Hypothyroidism

$P$ value $<0.05$ significant $(s=$ significant $)$

not significant
Table-IV

Distribution of study patients by diagnosis $(n=80)$

\begin{tabular}{|c|c|c|c|c|c|c|}
\hline \multirow[t]{2}{*}{ Diagnosis } & \multicolumn{2}{|c|}{$\begin{array}{l}\text { Group A } \\
(n=40)\end{array}$} & \multicolumn{2}{|c|}{$\begin{array}{l}\text { Group B1 } \\
(n=20)\end{array}$} & \multicolumn{2}{|c|}{$\begin{array}{l}\text { Group B2 } \\
(n=20)\end{array}$} \\
\hline & & $\%$ & & $\%$ & 11 & $\%$ \\
\hline \multicolumn{7}{|l|}{ Open angle } \\
\hline glavcoma & 3 & 7.5 & 1 & 5.0 & 1 & 5.0 \\
\hline \multicolumn{7}{|l|}{ Glavcoma } \\
\hline suspect & 2 & 5.0 & 1 & 5.0 & 0 & 0.0 \\
\hline \multicolumn{7}{|l|}{ Ocular } \\
\hline hypertension & 7 & 17.5 & 0 & 0.0 & 0 & $0.0^{*}$ \\
\hline Normal & 28 & 70.0 & 18 & 90.0 & 19 & $95.0^{*}$ \\
\hline
\end{tabular}

$*=\mathrm{P}<0.05$

Group A- TRIO

Group B1- Toxic multinodular goiter

Group B2- Hypothyroidism

OHT was found to occurred only in group A and difference was statistically significant $(\mathrm{p}<0.05)$.

Regarding IOP, 10 patients (25\%) in Group-A, 1 patient in Group-Bl (5\%), 1 patient in Group-B2 (5\%) had IOP $>21$ $\mathrm{mmHg}$ which is significantly $(\mathrm{p}<0.05)$ higher in Group-A. On gonioscopy all patients from Group-A, Group-B1 and Group-B2 have open angle (Table-I)

On fundoscopy, glaucomatous change was found in Group-A in 5 patients (12.2\%) out of 40, among them, 3 patients have OAG (7.5\%) and 2 patients have GS (5\%). In Group B1, 2 patients (10\%) out of 20 and in Group-B2, 1 patient $(5 \%)$ out of 20 have glaucomatous change. In Group-B1, 1 patient $(5 \%)$ have OAG and 1 patient $(5 \%)$ have GS, in Group-B2, 1 patient (5\%) have OAG.(Table-I)

In this study, glaucomatous change of visual field present in Group-A, 3 (7.5\%) patiens, Group-B1, 1 (5\%) and in Group-B2, 1 (5\%) patient, which is higher in Group-A than Group-B. In Group-A, all of 3 patients had OAG (7.5\%).(Table-II)

Exophthalmometric measurement shows, in Group-A $\leq$ $21 \mathrm{~mm}$ in $16(40 \%)$ patients and $\geq 22 \mathrm{~mm}$ in $24(60 \%)$ 
patients. In Group-B1 and B2, none of the patients have $\geq$ $22 \mathrm{~mm}$. So this study shows $\geq 22 \mathrm{~mm}$ measurement is significantly $(\mathrm{p}<0.05)$ higher in Group-A.(Table-III)

Regarding glaucoma diagnosis, Open anglae glaucoma (OAG) present in Group-A 3 (7.5\%) patients, in Group$\mathrm{B} 1$ one $(5 \%)$ patient and in Group-B2 one $(5 \%)$ patient which was not statistically significant $(p>0.05)$. Glaucoma suspect (GS) in Group-A $2(5 \%)$ patients, in Group-B1 one (5\%) patient, in Group-B2 0\% which is not statistically significant $(p>0.05)$. The OAG and GS are almost alike in these groups. But ocular hypertension (OHT) present, in Group-A 7 (17.5\%) patients, in GroupB1 and Group-B2 none have OHT, which is statistically significant $(p<0.05)$. So ocular hypertension is significantly higher in Group-A than Group-B.(Table-IV)

\section{Discussion:}

This comparative study was carried out with an aim to detect the relationship of open angle glaucoma (OAG), glaucoma suspect (GS) and ocular hypertension (OHT) in thyroid related immune orbitopatlly (TRIO/TAO) and other thyroid diseases (toxic multinodular goiter and hypothyroidism). In TAO patients had clinical feature of hyperthyroidism with ocular menifestations and biochemically. Anti THR antibody positive with high FT4 and low TSH level, in toxic multinodular goiter patients have clinical feature of hyperthyroidism and biochemicaliy hyperthyroid state, high/normal radioiodine uptake but negative Anti THR antibody and in hyperthyroidism patients had clinical features of hypothyroidism with high TSH and low FT4, FT3. After diagnosis patients were recruited in Group-A (thyroid related immune orbitopathy/TAO) and Group-B (other thyroid disease) which was subdivided into, Group-Bl includes toxic multinodular goiter and Group-B2 includes hypothyroidism as per inclusion and exclusion criteria. As Graves' diseases is a systemic disease, which may associated with ophthalmopathy so patients with ocular involvement were taken in account. All patients in our study were diagnosed as thyroid disease (GD/toxic multinodular goiter/hypothyroidism) in endocrine department, BSMMU were taken, relevant systemic and ocular (intraocular pressure, fundoscopy, gonioscopy, exophthalmometry, visual field) examinations were done and different parameters were compared between the groups.

Regarding IOP $>21 \mathrm{mmHg}$ present in $10,1,1$ patients respectively in Group A, B1 and B2 which was statistically significant. Behrouzi et al (2007) shows IOP $>21 \mathrm{mmHg}$ significantly higher in TRIO than normal population because in TRIO there is increased intra orbital volume due to soft tissue swelling which rises episcleral venous

\section{Conclusion:}

The present study shows ocular hypertension (OHT) is significantly higher $(\mathrm{p}<0.05)$ in patients with thyroid related immune orbitopathy than toxic multinodular goiter and hypothyroidism. There is no significant relation of open angle glaucoma (OAG) or glaucoma suspect (GS) in thyroid related immune orbitopathy with toxic multinodular goiter and hypothyroidism.

\section{Referrences:}

01. Prabhakar, B S. Bahn, R S. Smith, T J. Current perspective on the pathogenesis of Graves' disease and ophthalmopathy, Endocrine Reviews 2003; 24(6): 802-35.

02. Bartley, G B. Fatourechi, V. Kadrmas, E F. Jacobsen, S J. Ilstrup, D M. Garrity, J A. Gorman, C A.. The incidence of Graves ophthalmopathy in Olmsted County, Minnesota. American Joumal of Ophthalmology 1995;120(4):511-17.

03. Khan, A. Khan, M. Akhtar, S. Thyroid Disorders, Etiology and Prevalence, Joumal of Medical Science2002; 2(2): 89-94.

04. Holds, J.B. (2011) 'Section 7: Orbit, Eyelids, and Lacrimal Systen', in T.J. Liesegang (ed.) . Basic and Clinical Science Course(2011-2012). San Francisco: American Academy of Ophthalmology, pp. 47 .

05. Geoffery, J G. Nesi, F A. Thyroid eye disease and role of the TED specialist. Bulletin of Graves Disease and Thyroid foundation 2008; 87:2-4.

06. Bahn, R.S. Heufelder, A.E. Pathogenesis of Graves' Ophtha]mopathy, The New England Joumal of Medicine1993; 329: 1468-1475

07. Silva, F L da. Lourdes, V R M.de. Akaishi, P M. Cruz, A A. 
Graves' orbitopathy: frequency of ocular hypertension and glaucoma, Eye 2009,; 23(4): 957-59.

08. Hoogendoorn, E H. Hermus, A R. de Vegt, F. Ross, H A. Verbeek, A L. Kiemeney, L A. Swinkels, D W. Sweep, F C. den Heijer, M. Thyroid function and prevalence of anti-thyroperoxidase antibodies in a population with borderline sufficient iodine intake: influences of age and sex, Clinical Chemistry 2006; 52(1): 104-11.

09. Reid, J R. Wheeler, S F. Hyperthyroidism: diagnosis and treatment, American Fannily Physician 2005; 72(4): 623-30.

10. Randolph, G W. 'Chapter 7: Prevalence, pathogenesis \& natural history', in G.W. Randolph (ed.) Surgery of the Thyroid and Parathyroid Glands 2012, 2nd Edition. UK: Saunders: 725-30.

II. Larsen, P R.Davies, T F. Williams Textbook of Endocrinology 2002, 10th edition. USA: Elsevier Health Sciences:, 423-24.

12. Kalmann, R. Mourits, $\mathbf{M ~ P l}$. Prevalence and management of elevated intraocular pressure in patients with Graves' orbitopathy, British Joumal of Ophthalmology 1998; 82(7): 754-57.

13. Paul, A K. Miah, S R. Mamun, A A. Islam, S.Thyroid disorder in Khulna district: A community based study, Bangladesh Medical Research Council Bulletin 2006;32(3): 66-71.

14. Cioffi, G.A, editor. Basic and Clinical Science Course..American Academy of Ophthalmology'Section 10: Glaucoma', 2011-2012 San Francisco: 53-56.

15. Hasnat, M A. Rumi, M A K, Alam, MN. Hasan, K N. Salimuullah, M. Salam, M A. Fariduddin, M. Mahtab, H. Khan. A K. Status of antithyroid antibody in Bangladesh, Postgraduate Medical Journa 20001; 76: 345-49.

16. The World Health Report. Life in the 21 st century A vision for all. World Health Organization Geneva 1998: 113-15.
17. Thylefors. B. Négrel, A D. The global impact of glaucona, Bulletin of the World Health Organization 1994; 72(3): 323-26.

18. Rahman. M. Biochemical Status and Cytopathological Profile of Patients Presenting with Multinodular Goiter, Joumal Medicine 2011: 9:. 26-29.

19. Shields, M B. 'Intraocular pressure and tonometry', in S.E. Moroi, S.F. Freedman, K.F. Damji, R.R. Allingham, D.J. Rhee, M.B. Shields (ed.) Text Book of Glauconna 1998. 4th edition. Pennsylvania: Williams and Wilkins: 46-65.

20. Kanski, J.J. Bowling, B,editors. Clinical Ophthalmology: A Systematic Approach 2011, 7th Edition. UK: Expert Consult: 324-327.

21. Lee, A J. Rochtchinal, E. Wang, J J. Healey, P R. Mitchel, P. Open-angle glaucoma and systemic thyroid disease in an older population: The Blue Mountains Eye Study, Eye 2004; 18(6):. 600-08.

22. Cross, J M. Girkin, C A. Owsley, C. McGwin, Jr G.. The Association between Thyroid Problems and Glaucoma, British Joumal of Ophthalmology 2009; 92(11): 1503-1505.

23. Lyle, T K. Cook, C. Worths, M, editor. Disease of the Ey2011, 13th edition. Delhi: CBS Publisher: 389.

24. Fancois $\mathrm{J}$. The importance of sclera rigidity in intraocular Tonometry, Indian Journal of Ophthalmology, 1960; 8(1):16-24.

25. Behrouzi, Z Rabei, H Mohammad. Azizi, F. Daftarian, N Mehrabi, Y. Ardeshiri, M Mohammadpour, M. Prevalence of Open-angle Glaucoma, Glaucoma Suspect, and Ocular Hypertension in Thyroid-related Immune Orbitopathy, Journal of Glaucoma 2007; 16(4): 358-62. 